\title{
Crônica de um fracasso: Uma história dos projetos de criação de Universidades do Trabalho no Brasil
}

\author{
Marcela Alejandra Pronko
}

\begin{abstract}
RESUMO: Este trabalho pretende analisar, de uma perspectiva histórica, as propostas de criação da Universidade do Trabalho desenvolvidas no Brasil durante as décadas de 1930 a 1950, com especial atenção às elaboradas por Otner Boyse e Humberto Grande neste periodo. Partindo da análise da problemática político-educacional da época, sobretudo da que se refere ao ensino técnico profissional e de nível superior, tenta identificar os determinantes de sua não-materialização, com vistas a construir uma explicação para isso.
\end{abstract}

Palavras-chave: Universidade, trabalho, ensino técnico-profissional, ensino superior, Brasil

\section{As propostas de criação de Universidades do Trabalho no mundo}

A instituição universitária tem sido, desde seu surgimento, espaço permanente de disputa social e objeto recorrente de redefinições. Desde seu nascimento medieval, como corporação de estudantes ou professores, até as discussões atuais em relação às funções sociais que deve cumprir

\footnotetext{
* Este artigo constitui uma síntese da dissertação de mestrado "A universidade que não aconteceu. Uma análise das propostas de criação de Universidades do Trabalho no Brasil, nas décadas de 30 a 50", defendida na Faculdade de Educação da UFF, em agosto de 1997.

** Professora do Departamento de Educação da Universidade Nacional de Luján (Argentina) e doutoranda do Instituto de Ciências Humanas e Filosofia (ICHF) da Universidade Federal Fluminense.
} 
neste final de século e de milênio (universidade como empresa vs. universidade como agência social de incertezas), ${ }^{1}$ a universidade constituiu-se em centro de importantes debates políticos, cujo objetivo era delinear um perfil institucional em concordância com as sempre novas necessidades que colocava o processo histórico-social em curso.

Esse debate a respeito das finalidades e características que a instituição universitária deveria assumir se fez presente mais uma vez na primeira metade deste século, quando foi possível observar, em nível internacional, o surgimento de propostas educativas que objetivavam ostensivamente dirigir os estudos de nível médio e superior às necessidades específicas de formação técnico-profissional surgidas no âmbito do trabalho, por meio de instituições ditas universitárias. Essas instituições estavam destinadas aos novos grupos sociais que surgiram com o avanço do processo de industrialização e que não tinham espaço nos sistemas educativos tradicionais. Assim, com maior ou menor êxito, foram projetados universidades de novo tipo em diversos países: Université du travail (1902, Bélgica), Universidade do Trabalho (1934-1954, Brasil), Universidad del Trabajo (1942, Uruguai), Universidad Obrera Nacional (1948, Argentina), Universidad Laboral (1952, Espanha). Iniciativas semelhantes podem ser encontradas também no Chile, na Colômbia e na Venezuela. As décadas de 1940 e 1950 parecem ter sido particularmente frutíferas para a elaboração desse tipo de propostas.

Elas supunham não só uma reorientação curricular (passagem dos estudos humanísticos aos técnico-tecnológicos) e em termos de destinatários da universidade existente (da formação da elite dirigente à incorporação dos trabalhadores), mas também a definição de um novo modelo de universidade com características específicas, no contexto do estabelecimento de uma "nova sociedade" surgida como reação à queda do liberalismo, que se aprofundou na década de 1930 (Hobsbawm 1995) e que, na América Latina, estendeu-se até meados dos anos 50 (Halperin Donghi 1986).

Foi justamente na América Latina que surgiram neste período, em diferentes países e sob distintos regimes políticos, propostas institucionais do tipo das mencionadas. No Brasil, durante a era Vargas, ainda que nunca chegassem a institucionalizar-se, existiram - entre 1930 e 1955 - seis propostas distintas de criação de Universidades do Trabalho. Em 1942, o Uruguai, sob um regime de democracia liberal (1938-1943), criou a sua, e seis anos depois o governo peronista criaria na Argentina a chamada Universidad Obrera.

Como foi dito, tais instituições e propostas constituíram um sério questionamento ao ensino superior (liberal-humanista?) existente, e ofe- 
receram-se como alternativas a ele. Do mesmo modo, propunham-se como resposta política aos problemas sociais que o desenvolvimento da industrialização e o crescimento do operariado urbano colocaram. Se, por um lado, tratava-se de uma estratégia de integração dos setores sociais emergentes, por outro, respondiam às legítimas demandas de institucionalização de agências de formação de mão-de-obra, provenientes tanto do setor empresarial quanto do próprio operariado (Pineau 1991, Medeiros 1987).

Em todos os casos, o aparecimento desse tipo de propostas gerou amplos debates nos quais um dos eixos principais foi o da pertinência do nome adotado. É que já na sua própria denominação elas buscavam articular conceitos que, então (e até hoje), pareciam irreconciliáveis: UNIVERSIDADE (instituição de ensino superior, tradicionalmente reservada à formação da intelligentsia) e TRABALHO (domínio exclusivo da destreza manual/atividade produtiva desenvolvida pelos setores subalternos da sociedade). A polêmica suscitada não faz mais do que colocar em evidência a conflitividade da definição do que é (em termos de funções sociais) uma universidade, como instituição socioeducativa específica.

Mas, de todos os países mencionados, só o Brasil não instalou uma instituição como a descrita. Por isso, a consideração mais detalhada deste caso, que acrescenta a perspectiva do fracasso material da proposta, pode nos ajudar a entendê-la num contexto mais amplo.

\section{As propostas de criação de Universidades do Trabalho no Brasil}

As propostas de criação de Universidades do Trabalho estiveram presentes na história da educação brasileira durante todo este século. Desde 1922 até os dias atuais, com maior ou menor grau de definição, podem-se contar ao todo dez iniciativas dessa natureza. No entanto, foi durante as décadas de 1940 e 1950 que elas alcançaram seu maior desenvolvimento.

O processo global de ampliação das relações capitalistas no Brasil, que começou a acelerar-se na década de 1920, introduziu na sociedade brasileira múltiplas e novas questões a resolver. Por um lado, o impulso à industrialização, a incorporação de novos setores populacionais ao trabalho industrial e, como conseqüência, o crescimento das cidades e a aparição de novos atores sociais no cenário político agudizaram a "questão social" que já não podia ser tratada como uma "questão de polícia". Um dos problemas fundamentais que se colocava então era como 
integrar esses novos setores não apenas ao sistema produtivo como também ao sistema político (Weffort 1980). Por outro lado, com a expansão industrial, criaram-se novas necessidades para a indústria, tanto do ponto de vista da organização do trabalho, como da capacitação dos trabaIhadores.

Essas questões foram retomadas e assumidas pelo Estado antiliberal, marcadamente intervencionista, que se implantou no Brasil a partir da chamada Revolução de 30. Como esse Estado era, basicamente, um Estado de Compromisso (Fausto 1994), surgiram, em seu interior e a partir dos diferentes setores, diversas iniciativas orientadas ao encaminhamento de tais questões. Porém, nem todas obtiveram sucesso, dependendo da correlação de forças e da capacidade de negociação de cada uma em cada momento.

Uma dessas iniciativas foi o projeto de criação de uma Universidade do Trabalho que, no contexto enunciado, propunha-se a contribuir para a obtenção da harmonia social, propiciar a racionalização do processo produtivo e formar a mão-de-obra necessária ao crescimento industrial. Assim, essas propostas se colocaram no ponto de interseção de áreas educativas então em conflito: a da definição de um modelo de educação superior e a da definição de um modelo de formação técnico-profissional.

Efetivamente, as décadas de 1930 e 1940, no Brasil, assinalaram o momento de instalação, no debate político educacional, de uma nova problemática, fruto da articulação de duas esferas de atividade até então distanciadas: educação e trabalho. Ambas as áreas se constituíram, naquele momento, em objeto privilegiado da ação política desenvolvida pelo Estado. Assim, o seu próprio reordenamento, a regulamentação das relações de trabalho e a definição de um sistema educativo nacional constituíram respostas de peso à necessidade, que se colocava então, de ampliação das relações capitalistas neste país (Franco e Simon 1987).

De fato, foi durante os anos 40 que se definiram e se consolidaram diferentes propostas institucionais para o ensino técnico-profissional. Em 1942, e somente com alguns dias de diferença, foi criado o Senai (Serviço Nacional de Aprendizagem Industrial) ${ }^{2}$ e sancionada a Lei Orgânica de Ensino Industrial, ${ }^{3}$ que materializaram dois dos modelos em disputa pela definição da área. Ambos coexistiram, no decorrer dessa década e da seguinte, sofrendo alguns ajustes e modificações.

Por outro lado, e do ponto de vista da problemática estritamente universitária, os anos 30 significaram também um marco de grande importância. Em 1931, foi aprovado o Estatuto das Universidades Brasileiras, ${ }^{4}$ que 
adotou a universidade como modelo único desejado de organização didático-administrativa de ensino superior, fixando um modelo institucional de forma unívoca. Entretanto, durante sua vigência, assistiu-se ao nascimento de novas propostas institucionais, em muitos casos divergentes, entre as quais cabe ressaltar as de instituições universitárias de novo tipo.

Foi ao longo dessas três décadas, então, que se definiram tanto 0 caráter do ensino técnico-profissional quanto o modelo institucional da universidade brasileira. O que significou um processo de consolidação institucional no qual foram sendo deixadas de lado propostas alternativas, entre as quais estava a de criação de uma Universidade do Trabalho. Apesar da persistência com que foi apresentada, o fracasso dessa proposta foi uma constante na história da educação brasileira.

Dos seis projetos de criação de instituições desse tipo elaborados no Brasil entre 1930 e 1955, dois assumiram particular relevância pelo grau de definição atingido: o de autoria do belga Omer Buyse, redigido em 1934, e o produzido por Humberto Grande, 20 anos depois. Ainda que com laços de parentesco inegáveis, cada um deles delineou um perfil institucional bem característico. Examinemo-los brevemente.

\section{Os projetos de Omer Buyse}

Omer Buyse era um engenheiro belga dedicado à problemática do ensino técnico-profissional que havia participado da criação da Universidade do Trabalho de Charleroi (Bélgica) em 1902, transformando-se em caloroso difusor dessa instituição. No começo da década de 1930 e por sugestão de Fidelis Reis, introdutor dessa proposta no Brasil, Buyse foi convidado pelo governo varguista a realizar estudos sobre a organização e a instalação de tal instituição no país. Dessa encomenda, surgiu um anteprojeto não de uma e sim de três Universidades do Trabalho, com um alto grau de estruturação e desenvolvimento, entregue ao governo brasileiro em fins de $1934 .{ }^{5}$

O projeto desenvolvido por Buyse encontra justificação ideológica em alguns princípios fundamentais que ele próprio estabelece ao longo de sua obra. Para começar, a firme crença no valor do trabalho e na capacidade produtiva individual como bem social de uma nação. O meio de acrescentar esse valor individual, ou seja, a capacidade produtiva de cada indivíduo é, segundo Buyse, a formação profissional, que deve ser considerada agora sobre bases científicas. Desse modo, uma educação 
profissional racionalmente implementada constitui um recurso fundamental para a expansão da indústria e para o progresso de toda sociedade.

Assim, a formação profissional é útil, ao mesmo tempo, aos trabaIhadores, porque aumenta sua formação e contribui para seu bem-estar; aos industriais, porque lhes permite aumentar sua competitividade e seus lucros; e à nação, porque o crescimento industrial traz seu progresso. Finalmente, a formação profissional promove a harmonia social e contribui para o seu desenvolvimento.

Sobre essa base, Buyse fundamenta seu anteprojeto de criação de Universidades do Trabalho no Brasil, que se apresenta como o conjunto orgânico e centralizado das instituições fundamentais de ensino técnico de nível médio e superior. A estrutura acadêmica da instituição, de grande complexidade, abrange pelo menos três níveis de ensino, escolas de diversos tipos e para várias especialidades. Contudo, não se trata apenas de uma instituição de ensino. Contaria ainda com um organismo destinado basicamente a atividades de extensão e apoio à indústria.

A existência desse serviço obedecia ao fato de que a instituição projetada por Buyse (1914) tinha as seguintes funções:

a) a elevação da cultura técnica da massa trabalhadora;

b) o aperfeiçoamento dos métodos e sistemas de ensino industrial e profissional;

c) a difusão dos conhecimentos profissionais e das novidades técnicas para os representantes das indústrias e das classes médias.

Por isso, existe uma clara distinção, na argumentação do autor, entre a instituição por ele proposta e a universidade "tradicional", que se caracteriza por um tipo de ensino acadêmico ou liberal, distinção que é percebida por meio de vários elementos. Em primeiro lugar, na denominação de "Universidade do Trabalho", que, segundo Buyse, corresponde a uma nova forma de conceber a formação profissional, pensada agora de forma orgânica e dentro de um planejamento racional. Essa denominação não apresentaria grandes diferenças em relação à de "Universidade Técnica", porém se destacaria claramente dentro do quadro da uni- 
versidade de ensino "liberal". Esta última estaria dedicada, principalmente, ao desenvolvimento do conhecimento acadêmico, enquanto a instituição proposta teria seus objetivos orientados para a formação profissional e a difusão de conhecimentos práticos para a atividade produtiva.

Disso derivariam, para Buyse, múltiplas e marcantes diferenças, que iriam desde os conteúdos e as metodologias de ensino de uma e de outra até a titulação expedida e a própria organização institucional. No entanto, o projeto delineado por Buyse (com base em sua experiência na Bélgica), e enviado ao Brasil em 1934, não parece despertar maior interesse no então Ministro da Educação Gustavo Capanema que, percebendo inconvenientes na sua implementação, ${ }^{6}$ logo arquiva a proposta.

\section{A proposta de Humberto Grande}

Vinte anos depois, Humberto Grande, procurador da Justiça do Trabalho e propagandista da legislação trabalhista, retomaria a idéia, desenvolvendo a proposta de criação de uma instituição homônima, ainda que "autenticamente brasileira" (Grande 1956).

Ao longo de suas numerosas publicações, ${ }^{7}$ Grande delineia uma visão de mundo que vai servir de marco para a compreensão de seu projeto de universidade. O conceito central da mesma é o de trabalho. Para Grande, o trabalho é um elemento decisivo na sociedade, na medida em que constitui um fator dominante da cultura moderna. É, ao mesmo tempo, base da riqueza dos Estados, elemento agregador da nacionalidade, criador de valores culturais, utilidades e bens materiais e realizador da natureza humana. Por isso, o trabalho deve constituir o centro da política do Estado moderno, devendo ser considerado, então, como elemento definidor de um novo estatuto de cidadania. ${ }^{8} \mathrm{~A}$ cidadania passa a ser definida pela condição de trabalhador e caracterizada pela posse de determinados direitos sociais que o Estado "outorga" ao povo, em troca de sua cooperação.

Essa redefinição do conceito de cidadania é parte, por sua vez, de uma redefinição do conceito de democracia, que se distancia da ótica liberal. A democracia, definida segundo os valores do humanismo trabaIhista, não se carateriza pela posse de direitos políticos de cidadania, e sim pelo império da justiça social, corporificada na legislação do traba- 
Iho. Dessa forma, humanizando o trabalho (via legislação trabalhista), resolve-se a "questão social".

Por outro lado, assim como o trabalho se coloca como elemento organizador da sociedade, a organização deve ser uma característica especial do trabalho como eixo central do processo produtivo. Para Grande, a racionalidade aplicada ao processo de trabalho implica necessariamente a divisão social das tarefas, a distinção entre trabalho de direção e trabalho de execução. Desse modo, as diferenças sociais, conseqüência das capacidades diversificadas dos homens, refletidas nas distintas funções desenvolvidas no interior do processo produtivo, aparecem justificadas. Entretanto, seus efeitos sociais devem ser equilibrados pela ação do Estado, através da referida política do trabalho. A mesma deve tender à diminuição dos conflitos sociais, enquanto promove valores como a cooperação, a compreensão e solidariedade, em prol de um ideal de harmonia. Assim, combinando a racionalização do trabalho com o imperativo de justiça social, Grande orienta sua iniciativa.

A proposta de criação de uma Universidade do Trabalho aparece na obra de Humberto Grande no final da década de 1940 e início da década de $1950 .{ }^{9}$ Ao longo desta, desenvolvem-se algumas tentativas para concretizá-la, resultando, no entanto, infrutíferas. Essa proposta decorre dos princípios expressos ao longo da obra anterior do autor, que parecem cristalizar-se nela. Assim, a Universidade do Trabalho é apresentada como uma instituição educativa que, assumindo a importância do trabalho na sociedade moderna, transforma-o em tema universitário, repensando o papel que a universidade deve ocupar na sociedade. Com vistas a solucionar os problemas gerados pela "questão social", pretende, ao mesmo tempo, ampliar a pregação em favor da racionalização e da organização científica do trabalho e contribuir para a harmonia entre as classes ou para a conciliação social.

O projeto redigido em 1954 e publicado em 1956, ${ }^{10}$ ainda que conciso, oferece algumas indicações acerca do tipo de instituição que Grande pretendia: ela estaria sob a dependência do Ministério de Trabalho, Indústria e Comércio e integraria estabelecimentos de ensino tanto de nível médio como de nível superior. Contaria, por sua vez, com alguns institutos de investigação e pesquisa complementares. Ademais, absorveria em sua estrutura outras instituições relacionadas com o ensino técnico-profissional já existentes, como o Senai, e estaria articulada com a Fábrica Nacional de Motores, a Escola Técnica do Exército e a Usina Siderúrgica de Volta Redonda. 
De acordo com esse mesmo projeto, seriam objetivos da instituição proposta:

1. Formar e desenvolver a consciência do valor do trabalho na civilização.

2. Levantar o nível intelectual, moral e financeiro das massas.

3. Permitir o desabrochar do humanismo do trabalho.

4. Contribuir para o aperfeiçoamento das indústrias existentes.

5. Contribuir para a racionalização crescente do trabalho.

6. Ministrar o ensino em nível médio e superior a fim de habilitar o trabalhador ao exercício consciente de sua função.

7. Favorecer as pesquisas que visam ao conhecimento do mercado de trabalho, às condições exigidas para o exercício do mesmo, bem como à orientação e à seleção profissional. (Grande 1956, p. 8)

Todos os objetivos apontam, inequivocamente, em direção às duas grandes pretensões assinaladas anteriormente: ampliação da racionalização do processo de trabalho e conciliação social. As três primeiras tenderiam, inquestionavelmente, a desenvolver essa estratégia de conciliação, tentando "moldar" o trabalhador por meio de sua inserção na estrutura produtiva oferecendo-lhe, em troca, alguns ganhos de natureza principalmente simbólica. Tratar-se-ia, por um lado, de ocultar o caráter histórico da divisão social do trabalho, por meio da idealização do mesmo, via difusão de uma "ideologia do trabalho"11 (cultura trabalhista/humanismo do trabaIho, em palavras do próprio Grande); e, por outro lado, de oferecer certos benefícios materiais e simbólicos capazes de acalmar as insatisfações do setor (o acesso a uma cultura e a um nível de vida superior e, em linhas mais gerais, a obtenção do estatuto de cidadania, tal como foi definida).

Os outros quatro objetivos estariam ligados diretamente às necessidades da própria indústria, revelando, também, uma certa intencionalidade econômica do projeto, que atenderia, assim, a ambos os objetivos concomitamente, formando trabalhadores adequados às necessidades industriais e ajustados ao sistema social. Essa "conformidade" dos trabalhadores seria mais completa no marco da construção da harmonia social pela cooperação entre as classes, entre Capital e Trabalho. E, segundo Grande, a Universidade do Trabalho seria a instituição harmonizadora por excelência, porque nela seriam formados todos 
os níveis da escala ocupacional. Como disse Grande, tratava-se de formar: "homens de ação, chefes de indústrias, diretores de empresas, operários especializados e competentes, técnicos de toda ordem" (Grande 1956, p. 12), que cooperariam entre si sem importar as diferenças de classe, harmonizando as "massas" com as "classes dirigentes".

Assim, a Universidade do Trabalho deveria produzir a conciliação social e, ao mesmo tempo, formar a elite dirigente da economia e da sociedade. Contudo, isso não implicaria a transformação da instituição proposta em um reduto elitista e sim, pelo contrário, marcaria a essencialidade de seu caráter popular. Na medida em que a Universidade do Trabalho se propunha a formar a elite, através de uma educação prática e realista, estaria servindo ao povo, atendendo a seus verdadeiros interesses, isto é, ao desenvolvimento autônomo da nação.

Em conseqüência, a harmonização das classes, tendo por base a dignificação do trabalhador e o "ajustamento" das elites à realidade nacional, constituiria o verdadeiro caráter popular que, segundo Grande, a Universidade do Trabalho teria que adquirir. Ela se diferenciava, assim, da universidade então existente, que ele considerava ultrapassada, "fora dos tempos". Daí que a proposta de criação de uma Universidade do Trabalho viesse a completar o sistema universitário, atualizando-o. ${ }^{12}$

Em 1954, Humberto Grande chegou a presidir uma comissão criada pelo então Ministro de Educação e Cultura, Antônio Balbino, destinada a estudar as bases para a instalação de uma tal universidade. Alguns meses depois de iniciados os trabalhos, a morte do presidente Vargas encerraria mais uma vez suas possibilidades de materialização.

\section{Buyse e Grande: Um mesmo projeto?}

Ainda que Grande (1965) reivindique a originalidade de seu projeto como decorrência das necessidades da realidade nacional, quando comparamos os projetos de criação da Universidade do Trabalho dos dois autores, mesmo considerando as visíveis diferenças, aparecem muitos pontos de contato.

Para começar, em ambos os casos, a Universidade do Trabalho era definida como uma instituição centralizadora de todos os níveis da formação técnico-profissional, incluindo escolas e institutos de ensino médio e 
superior, assim como diversos organismos com funções de pesquisa e extensão, com intencional ingerência sobre o processo e o mercado de trabaIho. No caso de Buyse, essa centralização era regionalizada, com a proposta de criação de três instituições similares (no Recife, em Belo Horizonte e Porto Alegre), enquanto na definição de Grande aparecia uma única instituição.

Embora o anteprojeto de Buyse se detivesse mais no desenvolvimento dos aspectos acadêmico-institucionais e chegasse a delinear superficialmente a organização político-administrativa da universidade, elementos estes escassamente abordados na proposta de Grande, a concisa justificativa teórico-ideológica formulada pelo primeiro coincidia em suas linhas gerais com a colocada por este último. Em síntese, racionalização do processo produtivo e harmonia social constituíam pontos de partida comuns a ambos os projetos. Também os dois autores acentuavam a diferença das instituições propostas em relação à universidade existente. Tal diferença situava-se principalmente na capacidade de adaptação às necessidades econômicas do contexto, uma característica indissociável das Universidades do Trabalho, impossível de ser alcançada pelas outras. Desse modo, opunhase o ensino prático oferecido por uma instituição moderna e flexível ao ensino acadêmico realizado em uma instituição "ancorada na tradição" e, por isso, distanciada dos problemas suscitados pelos novos tempos.

Algumas dessas características seriam retomadas pelas propostas elaboradas posteriormente. No entanto, somente a Utramig (Universidade do Trabalho de Minas Gerais, 1965) chegaria efetivamente a ser criada e, ainda assim, rapidamente se descaracterizaria, fugindo aos padrões daquela proposta educativa. Esse permanente contraste entre persistência propositiva e fracasso material recorrente nos coloca no caminho da construção de algumas hipóteses explicativas que dêem conta de tal realidade.

\section{A caminho da construção de algumas hipóteses explicativas}

Traçar a história dos projetos de criação de Universidades do Trabalho, no Brasil, põe em evidência o conflito que permeia a definição institucional dos diferentes setores no campo educacional, precisamente porque nosso enfoque se situa na proposta que não foi bem-sucedida. Tentar compreender esse fracasso obriga-nos a desvendar o processo histórico, entendendo as instituições educativas, em um dado momento, como produto cristalizado de conflitos. 
Nesse sentido, não é possível construir uma explicação para o fracasso dessa iniciativa se não a situarmos no processo histórico, social e educacional em sentido amplo, observando ao mesmo tempo a dinâmica de sua resolução concreta. Dessa forma, constatamos que a variedade de propostas de criação de Universidades do Trabalho surgidas entre 1922 e $1936^{13}$ tinha por objetivo fornecer respostas à problemática de definição institucional relativa tanto à formação superior quanto ao ensino técnico-profissional. Em ambas as áreas, as propostas consideradas faziam parte de um conjunto mais amplo de iniciativas diversas. Foram incontáveis os projetos que, partindo de diferentes setores, tentaram definir um modelo para a formação técnico-profissional nesse período, o qual se mostrou igualmente fecundo em propostas e ensaios institucionais para a educação superior.

Embora o debate sobre o modelo institucional para ambas as áreas já estivesse presente na sociedade antes dos anos 30, foi a partir daí que o Estado passou a assumir um papel fundamental, incorporando-o à agenda governamental. Nesse contexto, muitas das mencionadas propostas surgiram em, ou por encomenda de, diferentes organismos estatais, como foi o caso do projeto desenvolvido por Omer Buyse que, apesar de sua extrema complexidade, não passou de mais um entre tantos outros. As propostas de criação de Universidades do Trabalho, nessa fase, inseriam-se no debate mais amplo produzido na época, relacionado com a definição institucional das referidas áreas educacionais.

Essa criatividade educacional - que tinha sido favorecida até aquele momento, em maior ou menor grau, por certa permeabilidade política amparada primeiro pelo funcionamento "liberal" da Primeira República e, depois, pela política de compromisso dos primeiros anos da chamada Revolução de 30 - foi interrompida em 1937 com a instauração do Estado Novo. A partir de então, o governo autoritário-corporativo centralizou no aparelho estatal a gestão de todos os possíveis conflitos, incorporando também todos os espaços abertos à negociação com determinados setores. No âmbito educativo, a partir de então e até 1945, processou-se a definição institucional para a formação técnico-profissional, e consolidaram-se as tendências que, para a educação superior, tinham começado a delinear-se no início da década. Curiosamente, durante esse período, não se conheceu nenhuma proposta de criação de uma Universidade do Trabalho.

Nos padrões desse sistema corporativo de representação social, a definição de um modelo de formação de força de trabalho necessária ao desenvolvimento industrial foi convertida em elemento de barganha polí- 
tica entre o Estado e o empresariado. Sua inclusão na pauta de negociações entre esses atores resultou em um longo processo que teve duas conseqüências básicas. Em primeiro lugar, a "cessão" ao empresariado, por parte do Estado, de uma parcela importante da formação profissional, assumindo perante ela uma responsabilidade restrita. ${ }^{14} \mathrm{Em}$ segundo lugar, a apropriação, um tanto reticente no início e entusiasmada posteriormente, dessa função por parte do empresariado industrial.

Nesse sentido, o estadonovismo produziu um fato insólito, pois o Estado, em nome de uma práxis política intervencionista, obrigou os industriais a se encarregar, com determinadas regras, dessa função educativa. Essa solução, que se revelou útil para o setor, sobreviveu à reimplantação da liberal-democracia no pós 45 , e essa parcela da formação profissional estruturou-se praticamente à margem do sistema de educação formal. No campo universitário, durante a vigência do Estado Novo, consolidaram-se as tendências à homogeneização institucional, definidas a partir da Revolução de 30. Desse ponto de vista, com a criação da Universidade do Brasil, como universidade-padrão, encerrou-se uma fase marcada por alta dose de "experimentalismo". ${ }^{15}$

As propostas de criação de Universidades do Trabalho só reapareceriam depois de 1945, quando uma certa abertura política deixou espaço à dissidência. Porém, no campo educacional, a arena de conflitos havia se povoado de novas problemáticas. O ressurgimento político de setores liberais e de esquerda, que lutavam pela democratização do ensino, colocou no centro do debate a necessidade de "correção" do sistema e de ampliação da oferta educativa.

Esses setores tencionavam, por um lado, reverter os efeitos diferenciadores de um ensino médio que, durante o Estado Novo, tinha sido definido em termos dualistas. Para tanto, promoveram as chamadas "leis de equivalência", que tinham por objetivo abrir uma passagem entre os diferentes ramos de ensino médio, especialmente entre os cursos profissionais e secundário, para favorecer a progressão de setores sociais cada vez mais amplos no sistema escolar (Cunha 1997). A primeira dessas leis surgiu em 1950 (lei 1.076/50) e outras se sucederam nos anos subseqüentes. Por outro lado, mas conseqüentemente, tratou-se de reformar a universidade existente, flexibilizando os mecanismos de articulação entre ensino médio e superior, a fim de facilitar o acesso a este último (Cunha 1997).

Foi nos marcos dessa discussão que surgiu a proposta de criação de uma Universidade do Trabalho, defendida por Humberto Grande no 
começo da década de 1950. A mesma consistia na montagem de uma instituição educacional que centralizaria todas as instâncias da formação profissional (desde as atividades de aprendizagem industrial até a formação de quadros de administração e gerência de nível superior). Tal instituição pretendia, em certo sentido, a racionalização do processo de seleção, capacitação e gerenciamento do mercado de trabalho em uma única instituição.

Nesse sentido, a proposta de Grande, do mesmo modo que as que surgiram depois dela, na medida em que retomavam a concepção de um sistema educativo dual, ${ }^{16}$ não se constituíam em uma iniciativa nem revolucionária, nem democratizadora. Pelo contrário, podia-se até mesmo considerá-las "reacionárias", visto que se apresentavam como alternativa institucional num contexto em que as lutas pela democratização educacional tendiam precisamente para a superação dessa dualidade.

Entretanto, não foi o seu conservadorismo a razão de seu insucesso. Acreditamos que outros elementos explicam melhor seu fracasso no plano material. De um lado, o projeto de Humberto Grande pretendia incorporar à Universidade do Trabalho, como instituição centralizadora do ensino técnico-profissional, aquela parcela desse tipo de formação que, "cedida" aos industriais pelo Estado na década de 1940, havia se estruturado fora do sistema educativo (e fora da dependência direta do Estado), e que não parecia gerar, por parte da sociedade, grandes questionamentos. Tal "cessão" poderia estar na base do fracasso de tais propostas formuladas após a década de 1940, já que estas pressupunham a responsabilidade direta do Estado sobre toda a formação profissional, e não somente sobre a formação de profissionais de nível superior, como efetivamente aconteceu. $\mathrm{Na}$ medida em que o Estado não reivindicou para si o espaço da formação profissional direta (por exemplo, como lugar privilegiado para a difusão da ideologia trabalhista a seu público específico), uma instituição como a que foi proposta apresentava sérias contradições com as linhas de política educacional adotadas nesse sentido.

Além do mais, quando Humberto Grande delineou seu projeto de criação de uma Universidade do Trabalho, o empresariado industrial estava mais consolidado e autônomo com respeito à ação estatal do que durante o Estado Novo. Convocado, pela Portaria ministerial $n^{\circ} 480 / 54$, para integrar a Comissão criada para estudar esse projeto, o setor tinha duas razões de peso para opor-se a ele ou, pelo menos, para não fomentá-lo. Em primeiro lugar, gerenciava um sistema de formação pro- 
fissional eficiente, que supria suas necessidades imediatas de preparação de mão-de-obra (Senai); e, em segundo lugar, o projeto se justificava por uma ideologia trabalhista a que os empresários sempre haviam resistido, sobretudo nos anos 50 .

Por outro lado, outros atores sociais tampouco o apoiariam. As organizações operárias não se interessavam pela proposta, apesar do apelo trabalhista, enquanto atores sociais com importância crescente, como os militares, defensores de um projeto modernizador, gestavam suas próprias instituições educacionais. Desse modo, a proposta de criação de uma Universidade do Trabalho ficou restrita a Grande e ao seu "entorno", isolada e inviabilizada.

Por seu turno, a mencionada proposta, tal como formulada em 1954, propunha-se a coroar a legislação trabalhista e se articulava coerentemente com uma forma corporativa de relação Estado/sociedade. Não por acaso Humberto Grande, seu principal promotor, era procurador da Justiça do Trabalho, reduto no qual, após a queda do Estado Novo, conservaram-se alguns princípios do corporativismo trabalhista. Na década de 1950 e nos limites dessa ideologia, seria o Direito, e não o Estado, que reivindicaria para si o papel de integrador das classes sociais (Vianna 1978).

Além do mais, se o trabalhismo já não era uma ideologia de Estado e estava restrito a determinados setores da sociedade, como construção ideológica tinha sido também redefinido, com a incorporação de setores da esquerda proscrita à estrutura partidária que a sustentava. Nesse contexto, a proposta de criação de uma Universidade do TrabaIho, que se autodefinia como trabalhista, não era vista com bons olhos pelos setores que comandavam os destinos do país.

Sintetizando o exposto, podemos dizer que a criação de uma Universidade do Trabalho propunha-se a ser uma resposta a vários problemas políticos, econômicos e sociais que a reordenação capitalista brasileira após os anos 30 e o conseqüente avanço do processo de industrialização impunham. Essa proposta foi gerada num ambiente de grande contestação ao ideário liberal e por isso implicava, para sua materialização, a existência de um Estado intervencionista que se colocasse acima dos conflitos sociais e os administrasse; um Estado com forte poder de intervenção no mercado de trabalho, guardando para si a função de formar trabalhadores, nas suas duas acepções: de prover uma capacitação técnica específica e inculcar uma ideologia do trabalho determinada, habilitando-os para isso. 
Porém, se a construção de um cidadão-trabalhador se configurou como tarefa fundamental durante o Estado Novo (Gomes 1994), isso não se refletiu numa política educativa específica. Nesse sentido, se o período se caraterizou pela constituição dos "trabalhadores do Brasil" como sujeito político e pela introdução da formação profissional como problemática educativa, a solução adotada estava longe de constituir o trabalhador em sujeito pedagógico privilegiado. $E$, entre outras coisas, isso se refletiu no fracasso de uma iniciativa como a de criação de uma Universidade do Trabalho.

Conseqüentemente, acreditamos que sua inviabilidade estaria relacionada ao fato de que, no plano educativo, o Estado brasileiro, após os anos 30 , reservou para si de modo privilegiado a formação das elites (daí a existência de uma política homogeneizadora do sistema universitário que excluía por definição as propostas de criação de universidades de novo tipo) e se desincumbiu da formação dos trabalhadores, "cedendo" uma parte significativa dessa responsabilidade ao empresariado.

Nesses termos, se um projeto educativo como o considerado já estava em conflito com a política educacional dominante desenvolvida durante o Estado Novo, posteriormente, seu anacronismo (político, ideológico e educativo) se aguçaria de forma crescente, ao definir-se como herdeiro de um momento político já parcialmente superado. Um exemplo disso foi o maior protesto de alguns setores sociais gerado pela tentativa de Jânio Quadros de instalar uma instituição desse tipo em $1961,{ }^{17}$ em comparação como projeto de Grande. Projeto esse que, encaminhado durante o segundo governo Vargas, conseguiu ainda algumas adesões.

Nesse ponto, então, podemos perguntar-nos sobre as razões da persistência do projeto. Acreditamos que tal persistência responde a duas questões fundamentais. De um lado, aos ganhos políticos auferidos do efeito simbólico do uso de um termo que, sob uma aparência democratizadora, esconde uma proposta educacional baseada na discriminação. Mas, por outro lado, também designa uma dívida social ainda em suspenso: a entrada do trabalho (como problemática e como ponto de vista) na universidade.

\section{Notas}

1. Tomamos o conceito de "universidade como agência social de incertezas" no sentido que lhe outorga Daniel Cano quando afirma que "hay varios siglos de vivencias y experiencias acumuladas por tras de la concepción de la 
Universidad como agencia social de incertidumbres, como asamblea o reunión de aquellos que aceptan el estado de duda en tanto modo privilegiado de producción del saber, como forma de organización social del trabajo que vincula a formuladores de preguntas inteligentes, a cuestionadores infatigables" (Cano 1996, p. 1).

2. Decreto-lei no 4.048 , de 22 de janeiro de 1942 .

3. Decreto-lei no 4.073, de 30 de janeiro de 1942.

4. Decreto-lei no 19.851 , de 1931.

5. A documentação que dá conta do anteprojeto é composta essencialmente de cartas e relatórios enviados por Buyse ao então Ministro de Educação Washington Pires, por intermédio da Embaixada do Brasil em Bruxelas, entre maio e novembro de 1934. Ela forma parte do Arquivo Gustavo Capanema, do Centro de Pesquisa e Documentação em História Contemporânea do Brasil, da Fundação Getúlio Vargas (CPDOC/FGV).

6. Capanema assinala: "É de notar que, dadas a grande extensão territorial e a pequena densidade demográphica do Brasil, nossa necessidade mais imperiosa não é criar Universidade do Trabalho, para preparo de todas espécies de operários, em vários pontos do território nacional. Será antes fundar grande número de escolas profissionais especializadas, que possam atender às exigências industriaes das várias regiões do país" (Arquivo Gustavo Capanema, 19 de novembro de 1934, p. 5, GC 34.07.24 g 0620).

7. Foram identificadas 35 publicações do autor, entre livros e artigos, realizadas de 1936 a 1967. Oito delas foram consultadas integralmente ao longo da pesquisa.

8. Dessa maneira, o autor estrutura um mapa social onde coloca o processo de trabalho no centro, cabendo a algumas instituições a tarefa de regular e administrar suas relações: principalmente o Estado e, em colaboração com este, os sindicatos e as corporações.

9. Segundo Telles (1980), baseada em afirmações do próprio Grande (1965), este teria iniciado a difusão de sua idéia acerca da necessidade de criação de uma Universidade do Trabalho no Brasil com artigos em jornais e revistas, conferências e livros, desde 1940. Entretanto, nosso levantamento das obras publicadas pelo citado autor indica o surgimento dessa proposta apenas em inícios da década de 1950.

10. Estamos nos referindo ao anteprojeto de lei de criação de uma Universidade do Trabalho, que Humberto Grande incluiu no seu livro Universidade do Trabalho, publicado em 1956.

11. O conceito é utilizado por Braga para designar a forma de regulação da sociedade de classes, a partir da difusão das relações sociais de produção capitalista no Brasil (Braga 1980). Ver também Carmo 1992.

12. É possível extrair, por oposição, através da caracterização que Grande realiza de sua Universidade do Trabalho, a idéia que ele mesmo tinha da univer- 
sidade que denomina "clássica". Assim, se a Universidade do Trabalho deveria ser atual, técnica e popular, objetiva, realística, prática e estimuladora de economia, a universidade existente era considerada anacrônica, clássica e elitista, tendenciosa, utópica, teórica e desinteressada.

13. Nesse período se formularam seis projetos diferentes de criação desse tipo de instituições.

14. Estamos nos referindo à criação, mediante decreto do Poder Executivo, do Senai (Sistema Nacional de Aprendizagem Industrial) em 1942. Esse sistema estava organizado sob a dependência da Confederação Nacional da Indústria $(\mathrm{CNI})$, que passou a gerenciar e financiar a formação técnico-profissional correspondente às necessidades imediatas do setor.

15. Nesse sentido, deve ser assinalado que, durante a primeira metade da década de 1930, não só existiram propostas de criação de Universidades do Trabalho, senão também foi legalmente criada (ainda que nunca tenha sido instituída) uma Universidade Técnica, ao tempo que persistiam as propostas de instalação de uma Universidade Popular.

16. As explicações disponíveis na historiografia educacional brasileira (Telles 1979 , Braga 1989 e Cunha 1989) põem em relevo esse caráter "dualizante", que conteria a proposta de criação desse tipo de instituição. Isto é, a articulação latente entre a seleção-estruturação de determinados conteúdos escolares (técnicoprofissionais) com determinados grupos sociais (classes subalternas) (Petitat 1994). Em outras palavras, essas explicações supõem a existência em tais propostas de uma intenção de definir redes educacionais paralelas, por meio das quais circulariam públicos escolares diversos: um circuito clássico-humanístico mais valorizado para a formação das classes dirigentes vs. um circuito técnico-profissional menos valorizado, associado às classes subalternas. Essa divisão entre ambos os circuitos corresponderia à divisão inerente à sociedade capitalista entre trabalho manual e trabalho intelectual.

17. Em 1961, o então presidente do Brasil, Jânio Quadros, impulsionou a criação de uma Universidade do Trabalho que chegou a ter forma legal, mas não a materializar-se. Apesar de a renúncia de Quadros ter inviabilizado a proposta, ela já tinha recebido numerosas críticas de distintos setores sociais, entre as quais as dos estudantes universitários (Telles 1979).

\section{Chronicle of a fairlure: A history of "Universidades do Trabalho" (Labour Universities) creation projects in Brazil.}

ABSTRACT: The author aims to analyse, in a historical perspective, the proposals for the establishment of "Universidades do Trabalho" (Labour Universities) presented during the 30's and the 50's in Brazil, particularly those advanced by Omer Buyse and Humberto 
Grande. Starting from the analysis of the polítical-educational issues of those days, especially those concerning technicalvocations and college education, the author tries to identify the reasons that impeded their implementation, seeking to formulate an explanation.

\section{Bibliografia}

BRAGA, Ubiracy de Souza. "Reflexões em torno do discurso político sobre a 'Universidade do Trabalho' no Brasil: Uma indicação de análise". Rio de Janeiro: PUC-RJ, 1989 (mimeo).

BUYSE, Omer. Une Université du Travail. Paris: Dunod \& Pirat, 1913.

CANO, Daniel. "Conversos, técnicos y caníbales o acerca de las desventuras de la pedagogía en el laberinto del Estado Malhechor". Versão revisada e ampliada da ponência apresentada no Seminario Internacional Políticas, Instituciones y Actores en Educación, Centro de Estudios Multidisciplinares, Buenos Aires, abril de 1996.

CARMO, Paulo Sérgio do. A ideologia do trabalho. São Paulo: Moderna, 1992.

CUNHA, Luiz Antônio. A universidade crítica. Rio de Janeiro: Francisco Alves, 1989.

. "Populismo e políticas educacionais no Brasil - 1930/61". Texto apresentado no 49 Congresso Mundial de Americanistas. Quito, 5-11 de julho de 1997.

FAUSTO, Boris. Revolução de 30, história e historiografia. São Paulo: Brasiliense, 1994.

FRANCO, Maria Aparecida Ciavatta e SIMON, Maria Célia M.N. "TrabaIho e educação: A reordenação necessária no contexto da Revolução de 30". Revista Brasileira de Estudos Pedagógicos. Brasília, 68 (160), set./dez. 1987.

GOMES, Angela de Castro. A invenção do trabalhismo. Rio de Janeiro: Relume-Dumará, 1994.

GRANDE, Humberto. "A Universidade do Trabalho". Rio de Janeiro: Serviço de documentação do MTIC, 1956. 
. A Universidade do Trabalho e o desajustamento entre massas e classes dirigentes. Departamento de Imprensa Nacional, s/l, 1965.

HALPERIN DONGHI, Tulio. Historia contemporanea de América Latina. Buenos Aires: Alianza Editorial, 1986.

HOBSBAWM, Eric. Era dos extremos. O breve século XX: 1914-1991. São Paulo: Companhia das Letras, 1995.

MEDEIROS, Marluce. Expansão capitalista e ensino industrial. Rio de Janeiro: Senai/DN, 1987.

PETITAT, André. Produção da escola/produção da sociedade. Porto Alegre: Artes Médicas, 1994.

PINEAU, Pablo. Sindicatos, Estado y educación técnica (1936-1968). Buenos Aires: Ceal, 1991.

TELLES, Sarah Silva. "Um projeto populista para o ensino: A Universidade do Trabalho". Educação \& Sociedade, ano 1, nº 3, 1979.

VIANNA, Luiz W. Liberalismo e sindicato no Brasil. Rio de Janeiro: Paz e Terra, 1978.

WEFFORT, Francisco. O populismo na política brasileira. Rio de Janeiro: Paz e Terra, 1980. 